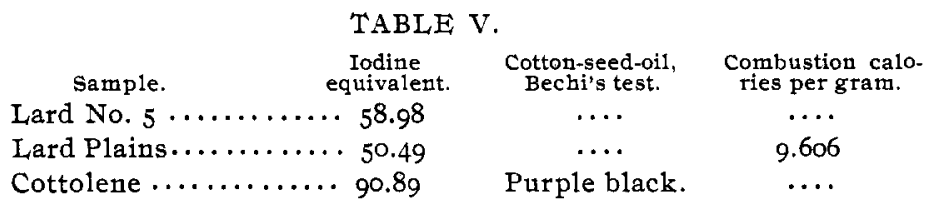

In addition two other samples of lard, one from Virginia, the other from Rhode Island, were examined. The samples sent with the inspectors' certificate were freshly made, while the other set was older material. There is a decided variation in the iodine equivalent and in deciding upon the character of the lard, the origin of the sample should undoubtedly be taken into consideration. As this is often not possible a check upon the other results may be secured by the determination of the calories.

BIOCHEMIC LABORATORY, WASHINGTON, D. C., December I4th, I895.

Discussion.-Mr. A. H. Sabin : I am very decidedly of the opinion that in investigations as to fats and oils, conclusive and satisfactory results can only be obtained by a comparison of methods. Such a method as this seems to me to be of a good deal of practical value because it is definite and positive. We make a combustion in this way and get some results which can be depended upon, and which can be verified; and the conditions are not difficult to duplicate. While I doubt if such a method will be of permanent value, because in such matters the ingenuity of the manufacturer is always pitted against the skill of the analyst, such a method always has weight, and must be taken in conjunction with other methods which also have weight and which also by themselves are not conclusive, but which have cumulative effect. I am certain that in regard to the vegetable fats it is only possible to arrive at just conclusions by a comparison of methods.

[CONTRIBUTIONS FROM THE CheMICAL LABORATORY OF THE U. S. DEPARTMENT OF AGRICULTURE. No. I6.]

NOTE ON THE USE OF ACETYLENE GAS AS AN ILLUMINANT FOR POLARISCOPIC WORK.'

THROITGH the courtesy of Prof. Charles E. Munroe, I was able to secure twenty-five kilos of calcium carbide for 1 Presented to the Washington Section, Dec. 9, 1895. 
experimental purposes, together with four burners. The acetylene was developed by the action of water on the calcium carbide and conducted into a small gas meter from which it was burned under a pressure of water, the flame being regulated by a stop-cock. The quantity of gas furnished by the calcium carbide is illustrated by the following experiment:

From ninety-five grams of carbide I I.5 liters of gas were obtained measured at a temperature of $18^{\circ}$. It is thus seen that one kilo of the calcium carbide nsed would furnish a little over 226 liters of gas.

The rate at which the gas was burned for furnishing the illumination for the polariscope was measured and found to be one liter each four minutes, measured under a pressure of thirty inches of water. The actual pressure at which the gas was burned was very much less than this, being regulated by the stop-cock. The lamp was thus supplied at a rate of consumption amounting to fifteen liters per hour.

The illumination produced by the burning acetylene was used with a triple shadow Schmidt \& Haensch double compensating polariscope and the accuracy of the readings with the intensely white light produced was tested with standard quartz plates. Two of the quartz plates read were standardized by the U. S. Coast and Geodetic Survey, in connection with this Division, and four were standardized by the Imperial German Commission of the Physical Institute at Berlin. The readings, to the nearest whole tenths, were as follows, at a temperature of $20^{\circ}$, which is slightly higher than that at which the quartz plates were standardized:

\begin{tabular}{|c|c|c|c|c|}
\hline \multicolumn{2}{|c|}{ Coast Survey tube } & \multicolumn{2}{|c|}{$92.06 \mathrm{read}$} & 92.1 \\
\hline ، & " & 99.06 & $\because$ & \\
\hline Gern & tube & $74 \cdot 45$ & ה & \\
\hline "، & ، & 93.59 & “ & \\
\hline ، & “ & 100.36 & " & $\infty$ \\
\hline " & " & -91.70 & " & \\
\hline
\end{tabular}

From the above readings it is seen that the light is absolutely reliable as tested against the best standards.

The degree of illumination was very great. The field of vision of the polariscope showed an intense illumination even at the neutral point and yet permitted of the reading of the shadow at 
the neutral point with the greatest accuracy. Three different observers in reading the quartz plates did not differ among themselves more than one-tenth of a degree.

A test was also made to determine the relative possibility of reading highly colored solutions with the acetylene light as compared with the ordinary kerosenes or gas illumination for the polariscope. A solution of "black strap" molasses was made, quite concentrated, without any clarifying agent whatever other than lead subacetate. The solution read in a 200 and $400 \mathrm{~mm}$. tube gave a perfectly distinct shadow with the acetylene light permitting the reading to within one-tenth of a degree. With the kerosene or lamp light, the field of vision was almost obscured at the neutral point and the readings made by three different observers differed as much as three-tenths of a degree. Another solution was made with the same black strap molasses without the use of any clarifying agent other than alumina cream. This was diluted to such a degree as to be distinctly read to within one or two-tenths of a degree by the acetylene light. When an attempt was made to read this same solution by the ordinary source of illumination, it was found that the field of vision was absolutely obscured, no light whatever passing through.

The results of these observations show that the acetylene light is perfectly reliable for polarizing purposes, that it produces an intense degree of illumination permitting of a very delicate distinction between the shadow and the illuminated portions of the field of vision, and permits the reading of solutions so highly colored as to be perfectly opaque to the ordinary sources of light.

The above results suggest also the practicability of using the acetylene light for microphotographic purposes and for ordinary photography, but I have not made any tests of its actinic power. The light can also be used for projections. It is to be observed that with the small quantity of calcium carbide obtained, viz., twenty-five kilos, there would be a sufficiency for almost a continuous polarization through a long period of time. With the cost of the calcium carbide known the actual cost of the light could be easily computed. I am ignorant, however, of the cost 
of the calcium carbide, it having been obtained for our use by the payment of the express charges only.

My thanks are due to Messrs. McElroy, Ewell, and Runyan for assistance in the preparation of the gas and in reading the polariscope.

\section{INDIRECT ANALYSIS.}

BY EDWARD $K$. LANDIS.

Received December 23, I895.

I $\mathrm{N}$ investigating this subject the author was struck with the 1 difference in the formulas given in the text-books and on trying some of the cases found the results did not agree. Supposing that the old atomic weights used in the formulas were the cause of the trouble, it was thought best to derive a formula in such a manner that it would apply equally if the present weights should be modified, and it is given herewith, trusting that it may be useful to many chemists in cases where a separation of the two elements is difficult or tedious.

It will apply to any case where the atomic weights of the two elements are not the same, and the greater the difference between the atomic weights the greater the accuracy. Unfortunately, nickel and cobalt cannot be determined in this manner, but many other elements can be. This method is especially convenient for sodium and potassium, and probably more accurate than the separation with platinum chloride.

\section{FIRST METHOD.}

Data given:

Weight of mixture.

Weight of common constituent.

Let $x=$ weight of salt with greatest per cent. of common constituent.

Let $y=$ weight of salt with least per cent. of common constituent.

Let $a=$ amount of common constituent in one part of $x$.

$b=$ " " " " " " " $"$ " $y$.

$W=$ weight of mixture.

$w="$ "common constituent. 